\title{
ЭКОЛОГИЯ
}

И ПРИРОДОПОЛЬЗОВАНИЕ

DOI: https://doi.org/10.15688/nsr.jvolsu.2018.4.4

UDC 502.175:502.51(470.45)

LBC 26.22(2P-4Вог)

\section{ASSESSMENT OF THE ECOLOGICAL STATUS OF ERIK THE SOUDOMOYKA WITHIN THE BOUNDARIES OF THE NATURAL PARK "VOLGA-AKHTUBA FLOODPLAIN"}

\author{
Alina V. Babicheva \\ Volgograd State University, Volgograd, Russian Federation \\ Nadejda V. German \\ Volgograd State University, Volgograd, Russian Federation
}

\begin{abstract}
The purpose our ecological and research is the research of one of transit reservoirs as a part of the Krasnoslobodsky water path of a northern part of the Volga-Akhtubinsk floodplain, regarding assessment of its ecological state. In a research bioindication methods, organoleptic, determination of amount of dissolved oxygen in water, definition of the PH environment, experimental definition dry were applied. In work the results of field and laboratory researches reflecting ecological and biological conditions of a reservoir of an erik the Soudomoyka during the period from March, 2017 to February, 2018 are presented. Therefore conclusions that the reservoir is polluted as Synedra, Spirogyra, Mougeotia number prevails as a part of algal flora were received. Water quality according to estimated data also excludes use of water of an erik the Soudomoyka by residents of nearby settlements for the economic and household purposes, the reservoir also does not meet the requirements for a sanitary state cannot be used in the recreational purposes.

Keywords: Volga-Akhtuba floodplain, erik the Soudomoyka, water pollution, ecological assessment, bioindication.
\end{abstract}

УДК 502.175:502.51(470.45)

ББК 26.22(2Р-4Вог)

ОЦЕНКА ЭКОЛОГИЧЕСКОГО СОСТОЯНИЯ ЕРИКА СУДОМОЙКА В ГРАНИЦАХ ПРИРОДНОГО ПАРКА «ВОЛГО-АХТУБИНСКАЯ ПОЙМА»

\author{
Алина Валентиновна Бабичева \\ Волгоградский государственный университет, г. Волгоград, Российская Федерация \\ Надежда Валерьевна Герман \\ Волгоградский государственный университет, г. Волгоград, Российская Федерация
}

Аннотация. Целью нашей эколого-исследовательской работы является изучение одного из транзитных водоемов в составе Краснослободского водного тракта северной части Волго-Ахтубинской поймы, на пред- 


\section{ЭКОЛОГИЯ И ПРИРОДОПОЛЬЗОВАНИЕ}

мет его экологического состояния. В исследовании применялись методы биоиндикаци, органолептики, определения количества растворенного кислорода в воде, РН-метрии, экспериментального определения сухого. В работе представлены результаты полевых и лабораторных исследований, отражающие экологическое и биологическое состояния водоема ер. Судомойка в период с марта 2017 года по февраль 2018 года. В результате чего были получены выводы о том, что водоем является загрязненным, так как численность Синедры (Synedra), Спирогиры (Spirogyra), Мужоции (Mougeotia) преобладает в составе альгофлоры. Качество воды по оценочным данным также исключает использование воды ерика Судомойка жителями близлежащих населенных пунктов для хозяйственно-бытовых целей, водоем также не отвечает требованиям по санитарному состоянию не может использоваться в рекреационных целях.

Ключевые слова: Волго-Ахтубинская пойма, ерик Судомойка, загрязнение воды, экологическая оценка, биоиндикация.

Введение. Проблемы качества пресной воды стоят достаточно остро как в региональном разрезе, так и на планетарном уровне. Поэтому систематические исследования непосредственно химического и биологического состава, экосистемных параметров конкретного водоема дает основание для актуальной оценки экологического состояния водоема и качества воды в нем.

Если оценивать проблему локально, а конкретно территорию Волго-Ахтубинской поймы, то в зоне ООПТ также существуют водоемы, которые подвержены антропогенной нагрузке и восстанавливаться «своими» силами не в состоянии из-за высокой интенсивности оказываемой нагрузки. Одним из таких водных объектов является ерик Судомойка, который относится к категории транзитных водотоков в составе Краснослободского водного тракта (КВТ). В настоящее время ерик существует в крайне неблагоприятных условиях, обусловленных размещением рекреационных зон, хозяйственным использованием (водозабор для полива сельхозяйственных угодий), наличием гидротехнических сооружений в запущенном состоянии (дамбы, водоотводы и водопропускные сооружения) и практическим отсутствием мероприятий по реабилитации ерика.

Вопросами оценки состояния водоема на территории Волгоградской области, в том числе водоемов Волго-Ахтубинской поймы посвящены исследования ряда авторов $[1,4,7$, $8,12,16]$. При реализации подобных исследований методы биоиндикации применяются достаточно часто и являются наиболее эффективными, поскольку оценивают качество воды опосредованно через состояние живых организмов и позволяют выстраивать законо- мерности динамики функционального состояния водоема. Что подтверждается достаточными объемами проводимых аналогичных исследований [5, 9-11, 14, 15].

Материалы и методы. В качестве объекта исследований был выбран ерик Судомойка, расположенный на территории Среднеахтубинского района Волгоградской области. Водоем входит в состав одного из двух крупных систем транзитных питающих водотоков северной части Волго-Ахтубинской поймы, его протяженность семь километров. В непосредственной близости, местами в границах водоохраной зоны, ерика расположены населенные пункты п. Сахарный, п. Песчанка и небольшая часть микрорайона города г. Краснослободск (см. рис. 1).

В ходе исследования применялись методы биоиндикации, органолептики, определения количества растворенного кислорода в воде, РН-метрии, экспериментального определения сухого остатка. Исследования по химическому составу и свойствам воды сопровождались отслеживанием температурного режима водоема.

Биологические исследования проводились ежемесячно в течение ряда лет. Для осуществления данного исследования использовали метод «раздавленная капля» и микроскоп ЛОМО, МИКРОМЕД-5 с разрешением $18 \times 40 ; 18 \times 10$.

Методы биоиндикации применимы только к водоемам, имеющим собственную биоту. Они учитывают реакцию на загрязнение целых сообществ водных организмов или же отдельных систематических групп. При этом исследователи непосредственно на водоеме учитывают факт присутствия в нем индикаторных организмов, их обилие, наличие у них патологических изменений. Несмотря на то, что и естественные условия водоемов, и виды заг- 
рязнений очень разнообразны, можно выделить несколько универсальных реакций сообществ водных организмов на ухудшение качества воды [11]. Прежде всего это: уменьшение видового разнообразия (в 2-4, а иногда и в десятки раз); изменение обилия водных организмов; смена типа питания водных организмов.

Причем обилие может как снижаться (при очень высоком уровне загрязнения или при наличии токсичных соединений), так и расти по сравнению с нормальным состоянием сообщества. Этот рост объясняется тем, что в водоемах, особенно при их загрязнении органическими веществами, могут оставаться немногие, но устойчивые к загрязнению виды животных. В таких условиях они достигают очень высокого обилия [5].

Именно эти закономерности применяются во многих методиках биоиндикации. К их числу относятся индексы видового разнообра- зия и методы, учитывающие соотношение обилия разных групп водных организмов. Кроме этого, часто учитывается способность определенных групп организмов обитать в водоемах с тем или иным уровнем загрязненности.

Известно, что представители любой надвидовой систематической группы (рода, семейства, отряда) практически никогда не обладают одинаковыми экологическими потребностями $[7,8,12]$. В состав таких групп могут входить совершенно разные с точки зрения отношения к загрязнению виды: устойчивые к загрязнителям, неустойчивые, видыуниверсалы, способные жить в очень широком спектре внешних условий и т. д.

Одной из распространенных ошибок является использование надвидовых таксонов как индикаторов качества воды без критического рассмотрения набора входящих в этот таксон видов [3].

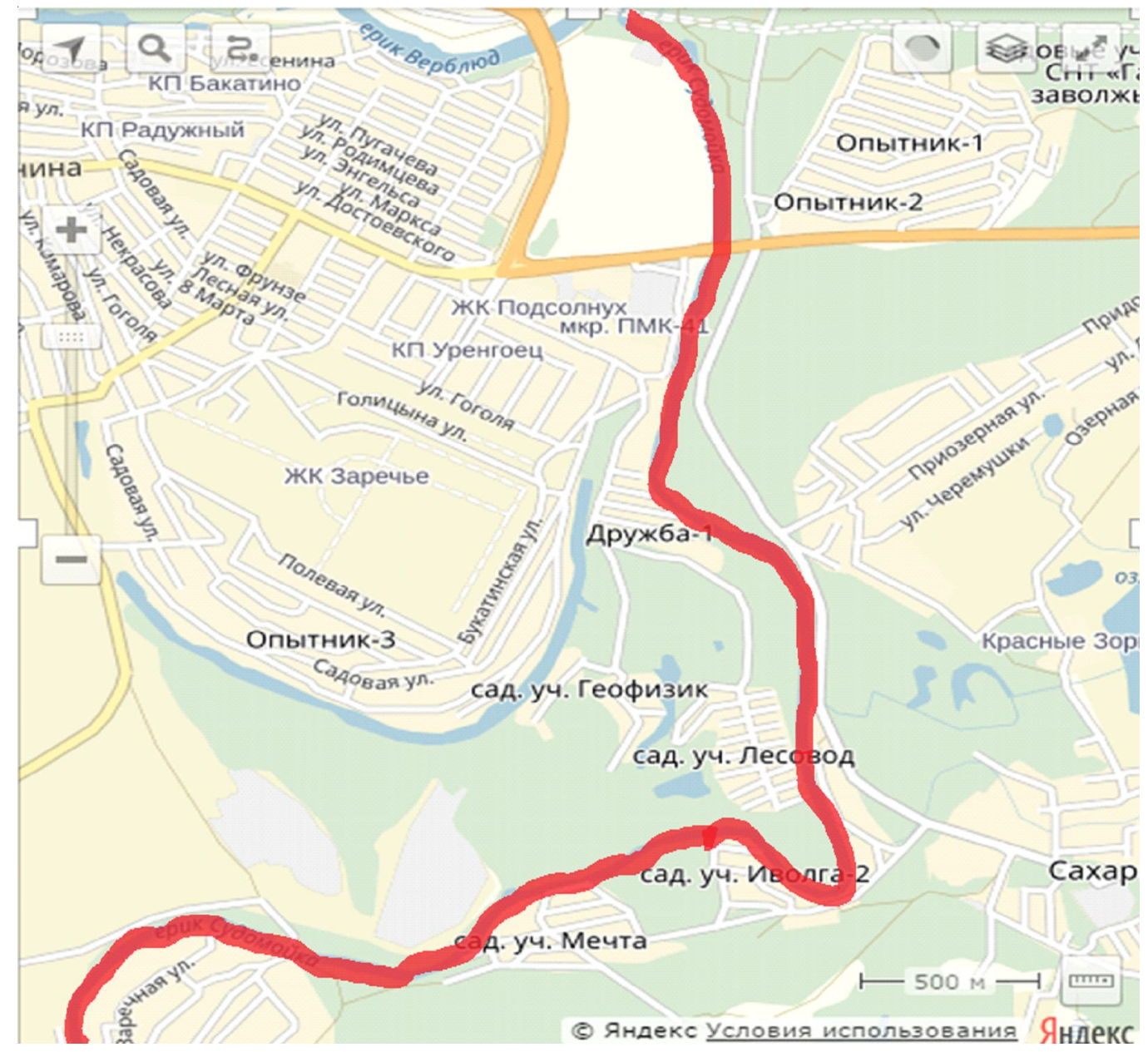

Рис.1. Местоположение ерика Судомойка на территории Среднеахтубинского муниципального района Волгоградской области 


\section{ЭКОЛОГИЯ И ПРИРОДОПОЛЬЗОВАНИЕ}

В нашем случае биоиндикаторами экологического состояния ерика служили водоросли, представители родов Nitzschia, Synedra, Spirogyra, Mougeotia, Gymnozyga и одноклеточные организмы.

При органолептическом анализе измерительным прибором являются органы чувств человека, а сам анализ представляет собой психофизиологический процесс. По нормативам необходимо осуществлять два замера показателей воды при комнатной температуре и при температуре $+60{ }^{\circ} \mathrm{C}$.

Температура воды - один из главных факторов, влияющий на протекающие в водоеме химические, биохимические, физические и биологические процессы, от которого в большей степени зависят интенсивность процессов самоочищения и кислородный режим [10]. Имеет большое значение для оценки экологического и санитарного состояния водоема содержание растворенного кислорода. В серию экспериментов в период с марта 2017 года по сентябрь 2017 года входило измерение растворенного кислорода в воде водоема с использованием переносного оборудования - анализатора растворенного кислорода «МАРК 302Э».

Для определения степени минерализации воды в водоеме был выбран способ экспериментального определения сухого остатка, так как он наиболее универсален. Для эксперимента требуются стандартное оборудование: термостат (Баня водяная лабораторные DZKW на 6 мест) и сухожаровой шкаф (Шкаф сушильный ШС-80-01-СПУ), аналитические весы (ATX/ATY Shimadzu), a также потребуются фарфоровые чашки, мерная посуда и лабораторная посуда общего назначения. Перед началом эксперимента необходимо фарфоровую чашку поместить в сухожаровой шкаф на 2 часа, затем остудить ее и взвесить. Параллельно с этим, исследуемую воду необходимо отфильтровать. Затем поставить фарфоровую чашку на предварительно разогретый термостат $\left(+100^{\circ} \mathrm{C}\right)$. До того пока вся исследуемая вода не выкипит, чашку не снимать. После необходимо поставить ее в сухожаровой шкаф еще на 2 часа и провести аналогичные действия и произвести расчеты по формуле, где X (мг/дм³) [3, 13]:

$$
x=\frac{(m-m 1) \times 1000}{V}
$$

где $\mathrm{m}$ - значение массы емкости с сухим остатком, мг; m1 - значение массы пустой емкости, мг; V - количество воды, взятой для испытания, $\mathrm{cm}^{3}$.

Результаты исследования и обсуждение. Данный водоем существует в условиях высокой антропогенной нагрузки, ввиду большого количества поселений, дачных массивов и рекреационных зон, как вдоль водоема, так и на прилегающей территории $[4,16]$. Эти факторы обуславливают экологическое состояние ерика Судомойка в настоящее время. Ввиду того, что вода из водоема используется для сельскохозяйственных нужд, так же на осуществление основного водного питания Волго-Ахтубинской поймы, то было принято решение о сериях экспериментов и исследований и проведении экологического мониторинга ерика Судомойка.

В результате биологического метода исследования нами были обнаружены микроорганизмы, которые служат биоиндикаторами качества воды. Следует сказать, что водоросли питаются с помощью фотосинтеза, но они способны менять тип питания на фоторедукционный, фотогетеротофный, автогетеротрофный, гетероавтоорофный и даже полный гетеротрофный тип при наличии в водоеме органических веществ, которые они используют в качестве дополнительного источника питания. Количество микроорганизмов в водоеме напрямую зависит от температурного режима и количества растворенного кислорода в воде. Из представленных организмов (см. табл. 1) за неблагоприятное состояние водоема отвечает высокое присутствие спирогиры и синедры [11].

Присутствие указанных видов свидетельствует, что данный водоем подвержен образованию тины. В середине лета температура воды увеличивается, а вместе с ней увеличивается численность представителей рода синедра (Synedra), что говорит о наличии различных загрязнений. Присутствие представителей рода спирогира (Spirogyra), также называемой «тина», встречается в пресных водоемах и связано с содержанием в воде большого количества органики. Род мужоция (Mougeotia) также преобладает в загрязненных водоемах [6]. Исходя из вышеперечислен- 
ных данных, можно сделать заключение о том, что данный водоем загрязнен и покрыт тиной в летний период. Наличие такого количества данных микроорганизмов говорит о перенасыщении кислорода в воде, особенно в дневной период, и как следствие острая нехватка кислорода в ночное время из-за перенаселения фитопланктоном. Поступление кислорода в воду происходит только за счет фотосинтеза водорослей и из атмосферного воздуха в дневное время, в ночное время концентрация кислорода снижается до минимума.

Зимой в пробах воды ерика было обнаружено большое количество слизи, яйцекладок различных насекомых, а также органического осадка, что также свидетельствует о загрязнении водоема в зимний период.

Данные за 2018 год несущественно изменились за год (табл. 2). Но динамика есть, так как в весенне-летний период проходила отчистка дамбы и небольшого участка дна ерика. Можно предположить, что действия были недостаточными для возобновления экосистемы водоема.

Продуктивность и урожайность микроскопических водорослей зависит от концентрации питательных веществ в окружающей среде. Из минеральных веществ для водорослей необходимы соли азота и фосфора [2]. Средняя концентрация этих веществ водоемах очень мала и поэтому высокая продуктив- ность фитопланктона, возможна лишь при условии постоянного поступления минеральных веществ в верхний слой воды - в зону фотосинтеза $[1,14]$. Также немаловажный фактор - слабая турбулентность водоема, то есть слабое течение или отсутствие такового. Следствием этого является чрезмерно бурное развитие фитопланктона (цветение воды), при разложении которого выделяется сероводород и другие токсичные соединения. Это приводит к гибели обитателей водоема и делает воду непригодной для хозяйственно-бытового использования. Массовое развитие водорослей связано с повышением температуры. Это, как правило, происходит во второй половине весны и летом, иногда в начале осени, если она теплая.

Определение органолептических показателей воды осуществлялось в лабораторных условиях. При температуре $+20^{\circ} \mathrm{C}$ запах у воды был землистый; цвет отсутствовал; вода отличалась сладким вкусом с привкусом мела; прозрачность составляла более 30. При температуре $+60{ }^{\circ} \mathrm{C}$ : запах землисто-болотный; все остальные показатели после нагревания не изменили свой характер. Можно предположить, что изменения не явные, так как эксперимент был проведен ранней весной и еще не все процессы были запущенны.

При исследовании температурного и кислородного режима в июле и сентябре были за-

Таблица 1

Виды микроорганизмов, обнаруженные в пробах воды ерика Судомойка (2017 год)

\begin{tabular}{|l|c|c|c|c|c|c|}
\hline \multirow{2}{*}{\multicolumn{1}{|c|}{ Виды организмов }} & \multicolumn{5}{|c|}{ Период проведения исследований в течение 2017 года } \\
\cline { 2 - 7 } & Март & Апрель & Май & Июль & Сентябрь & Декабрь \\
\hline Род нитцшия (Nitzschia) & 7 & 13 & - & 16 & - & 2 \\
\hline Род синедра (Synedra) & 13 & 10 & 9 & 20 & 17 & - \\
\hline Циклоп (Cyclopidae) & 2 & 1 & - & 6 & 3 & - \\
\hline Род спирогира (Spirogyra) & - & 15 & 9 & 25 & 27 & 5 \\
\hline Род мужоция (Mougeotia) & - & - & 2 & 6 & - & - \\
\hline Род гимнозига (Gymnozyga) & - & - & 3 & 9 & - & - \\
\hline
\end{tabular}

Таблицуа 2

Виды микроорганизмов, обнаруженные в пробах воды ерика Судомойка (2018 год)

\begin{tabular}{|l|c|c|c|c|c|c|}
\hline \multirow{2}{*}{ Виды организмов } & \multicolumn{5}{|c|}{ Период проведения исследований в течение 2018 года } \\
\cline { 2 - 7 } & Март & Апрель & Май & Июль & Сентябрь & Октбрь \\
\hline Род нитцшия (Nitzschia) & 4 & 7 & 15 & 16 & 9 & 5 \\
\hline Род синедра (Synedra) & - & 12 & 9 & 25 & 17 & 10 \\
\hline Циклоп (Cyclopidae) & - & 1 & 6 & 7 & 3 & - \\
\hline Род спирогира (Spirogyra) & - & 1 & 1 & 20 & 27 & 9 \\
\hline Род мужоция (Mougeotia) & - & - & 5 & 8 & - & - \\
\hline Род Гимнозига (Gymnozyga) & - & - & 2 & 5 & - & - \\
\hline
\end{tabular}




\section{ЭКОЛОГИЯ И ПРИРОДОПОЛЬЗОВАНИЕ}

фиксированы скачки уровня кислорода. Можно предположить, что повышение содержания кислорода произошло за счет увеличения количества водорослей в тот же период. При повышенной температуре водорослям комфортно, и они активируют свою жизнедеятельность.

В ходе эксперимента экспериментальному определению сухого остатка наблюдалось повышение минерализации воды в марте и июле 2017 года, что связано с отсутствием сброса воды Волжской ГЭС в указанные промежутки времени (рис. 2). Такое явление, может охарактеризоваться несколькими явными причинами - это антропогенная деятельность на истоке, также рекреационная деятельность, производимая летом в специально отведенных местах и засор дамб по всей территории водоема. Более выраженные скачки произошли зимой, что не характерно для данного времени года. Такое явление, возможно, обусловлено повышением количества синезеленых водорослей зимой (табл. 1), которые являются показателем загрязненных вод. Исследования 2018 года показали большой скачок в феврале и сентябре (рис. 3).

Рассматривая внешние признаки водоема, нужно отметить, что на период паводка отмечался сильный подъем воды, что отразилось в заметных переменах в показателях эксперимента «сухой остаток».

Выводы. Ерик Судомойка относится к транзитным водотокам Волго-Ахтубинской поймы и при этом подвергается активным антропогенным нагрузкам, так как находится в непосредственной близости к населенным пунктам. Поскольку транзитные водотоки оказывают большое влияние на природные комплексы поймы, качество воды в них напрямую влияет на состояние всего комплекса в целом. Береговая линия ерика весьма существенно загрязнена бытовыми отходами, что подтверждает антропогенное воздействие на экосистему водоема преимущественно в зимний период $[9,15]$. По вышеперечисленным данным, можно сказать, что в ерике Судомойка качество воды неудовлетворительное, и он относится к слабо загрязненным. Несмотря на неблагоприятное экологическое состояние водоема, местные жители продолжают пользоваться водой, подвергая опасности свое здоровье. Однако, на территории северной части Волго-Ахтубинской поймы в 2018 году начались мероприятия по реабилитации ериков, одним из которых стал ерик Судомойка. К на-

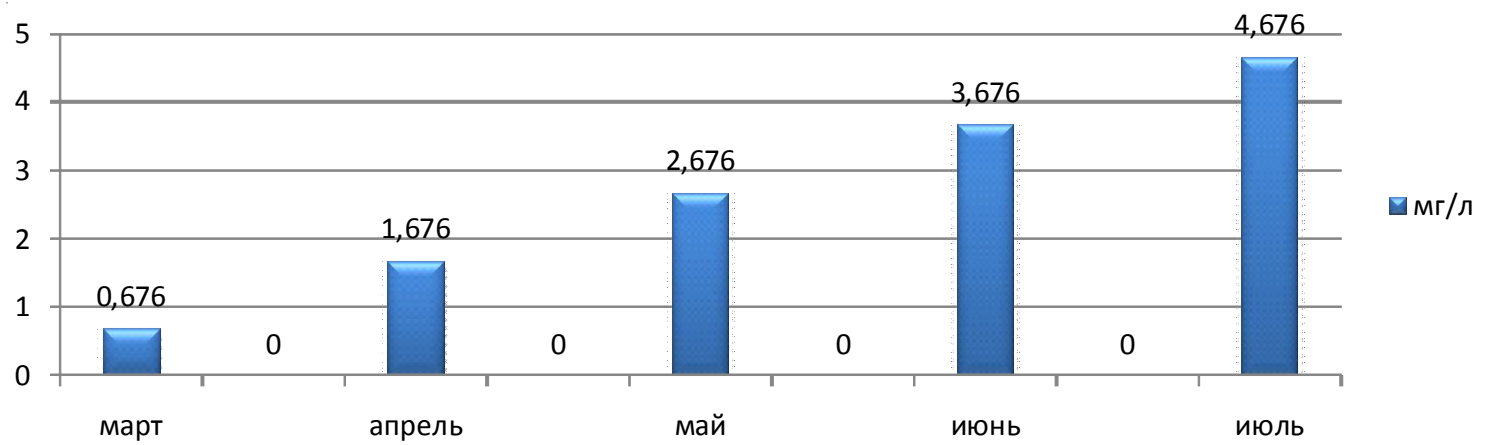

Рис. 2. Результаты экспериментального определения сухого остатка воды ер. Судомойка за 2017 год

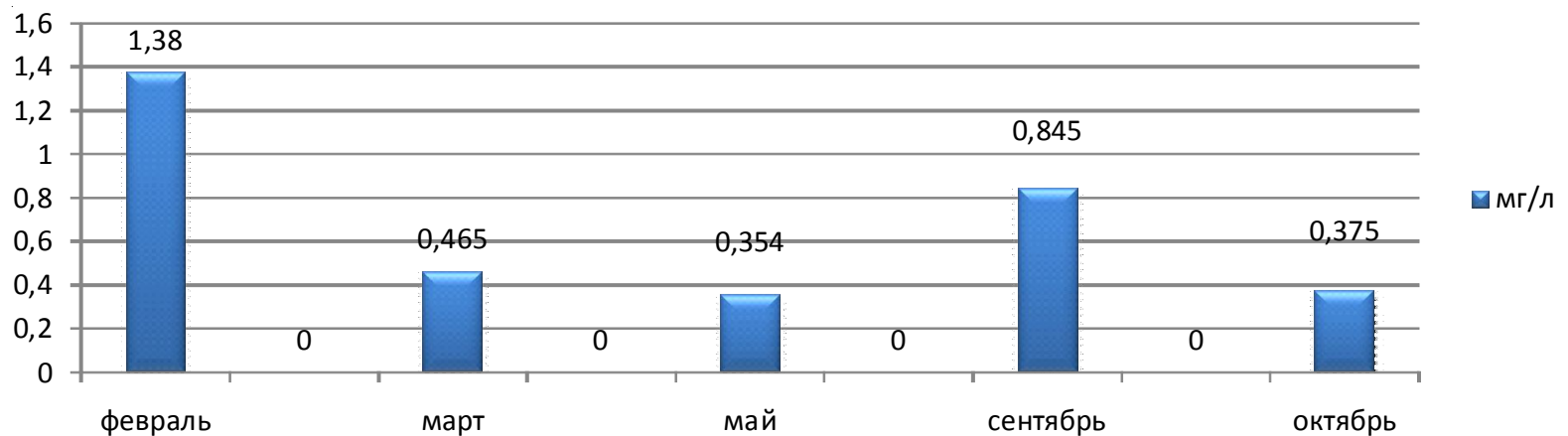

Рис. 3. Результаты экспериментального определения сухого остатка воды ер. Судомойка за 2018 год 
стоящему моменту расчистка и ремонт гидротехнических сооружений (отремонтированы водовыпуски, установлены новые затворы) на ериках Сахарный, Судомойка и озере Запорное реализованы на $40 \%$, что позволяет надеяться на изменение экологического состояния водных объектов при улучшении их водного питания.

\section{СПИСОК ЛИТЕРАТУРЫ}

1. Алешня, В.В. Значение индикаторных микроорганизмов при оценке микробного риска в возникновении эпидемической опасности при питьевом водопользовании / В.В. Алешня, П.В. Журавлев, С.В. Головина // Гигиена и санитария. -2008. № 2. - С. 23-27.

2. Алимов, А.Ф. Разнообразие, сложность, стабильность, выносливость экологических систем / А.Ф. Алимов// Журнал общей биологии. - 1994. Т. 55. - № 3. - С. 285-302.

3. Базилевич, Н.И. Географические закономерности продуктивности и круговорота химических элементов в основных типах растительности Земли / Н.И. Базилевич, Л.Е. Родин // Общие теоретические проблемы биологической продуктивности. - Л.: Наука, 1969. - С. 24-33.

4. Баранова, М.С. Подходы к реанимации водотоков и водных систем Волго-Ахтубинской поймы (на примере Краснослободского водохозяйственного тракта) / М.С. Баранова, О.В. Филиппов, А.И. Кочеткова, Е.С. Брызгалина // Электронный научно-образовательный журнал ВГСПУ «Грани Познания». - № 4(38). - 2015. - С. 94-103.

5. Бойцов, А.Г. Оценка качества воды по биологическим показателям: пути совершенствования / А.Г. Бойцов, О.Н. Ластовка, Г.П. Кашкарова, О.Е. Благова // Гигиена и санитария. - 2005. № 1. - С. 74-77.

6. Будаговский, А.И. Ресурсы почвенных вод и водообеспеченность растительного покрова / А.И. Будаговский // Водные ресурсы. - 1985. - № 4. - С. 3-13.

7. Иванцова, Е.А. Альгомониторинг разнотипных водоемов Волгоградской области / Е.А. Иванцова, А.С. Карабская // Вестник Волгоградского государственного университета. Серия 3. Экономика. Экология. - 2016. - № 1 (34). - С. 161-168.

8. Карабская, А.С. Состав альгоценозов разнотипных водоемов Волгоградской области /А.С. Карабская, Е.А. Иванцова // Вестник Нижневартовского государственного университета. - 2017. - № 4. - С. 4-8.

9. Коломин Ю.М. Экологический мониторинг состояния водоемов северо-казахстанской области и использование их биоресурсов / Ю.М. Коломин // Экологический мониторинг и биоразнообразие: материалы IV международной научно-практической конференции, 18-19 апреля 2012 года, г. Ишим [отв. ред. А. Ю. Левых]. - Ишим: ФГБОУ ВПО Ишимский гос. пед. ин-т им. П. П. Ершова, 2012. - С. 110-113.

10. Курамшина, Н.Г. Комплексный экологический мониторинг водных экосистем в условиях техногенеза / Н.Г. Курамшина, Э.М. Курамшин, В.В. Лапиков // Экологические системы и приборы. - 2004. - № 8. - С.9-11.

11. Леванова, Г.Ф. Экспресс-метод биотестирования воды в полевых условиях / Г.Ф. Леванова, В.Н. Мазепа, С.Ю. Кашников // Гигиена и санитария, 2004. № 1. С. 64-66.

12. Новиков, В.В. Экологическая оценка Волгоградского водохранилища по состоянию макрофитов и фитопланктона / В.В. Новиков, А.С. Карабская, А.И. Кочеткова, Е.А. Иванцова, В.П. Зволинский // Вестник Российского университета Дружбы народов. Серия: Экология и безопасность жизнедеятельности. - 2014. - № 4. - С. 120-132.

13. Онищенко, Г.Г. Состояние питьевого водоснабжения в Российской Федерации: проблемы и пути решения / Г.Г. Онищенко// Гигиена и санитария. -2007 . - № 1. - С. 10-13.

14. Петров, Б.И. Фазовые равновесия и распределение элементов в системах вода - антипирин органическая кислота / Б.И. Петров, С.А. Денисова, А.Е. Леснов // Известия Алт. гос. ун-та. - 2003. № 3 (29). - С. 230-236.

15. Рахманин, Ю.А. Приоритетные направления и критерии оценки загрязнения окружающей среды / Ю. А. Рахманин // Гигиена и санитария. 2003. - № 6. - С. 14-16.

16. Филиппов, О.В. Экологическая оценка состояния водных объектов Волго-Ахтубинской поймы в условиях зимнего периода 2014-2015 гг. / О.В. Филиппов, А.И. Кочеткова, М.С. Баранова, Е.С. Брызгалина // Электронный научно-образовательный журнал ВГСПУ «Грани Познания». - №4(38). -2015. - С. 104 113. - Режим доступа: http://grani.vspu.ru/jurnal/40.

\section{REFERENCES}

1. Aleshnja V.V., Zhuravlev P.V., Golovina S.V. i dr. Znachenie indikatornyh mikroorganizmov pri ocenke mikrobnogo riska $\mathrm{v}$ vozniknovenii jepidemicheskoj opasnosti pri pit'evom vodopol'zovanii [The value of indicator microorganisms in the assessment of microbial risk in the occurrence of epidemic danger in drinking water use]// Gigiena i sanitarija [Hygiene and sanitation], 2008. № 2. S. 23-27.

2. Alimov A.F. Raznoobrazie, slozhnost', stabil'nost', vynoslivost' jekologicheskih sistem [Diversity, complexity, stability, endurance of 


\section{ЭКОЛОГИЯ И ПРИРОДОПОЛЬЗОВАНИЕ}

ecological systems] // Zhurnal obshhej biologii. 1994. T. 55. № 3. S. 285-302.

3. Bazilevich N.I., Rodin L.E. Geograficheskie zakonomernosti produktivnosti i krugovorota himicheskih jelementov $\mathrm{v}$ osnovnyh tipah rastitel'nosti Zemli // Obshhie teoreticheskie problemy biologicheskoj produktivnosti. L.: Nauka, 1969. S. 24-33.

4. Baranova M.S., Filippov O.V., Kochetkova A.I., Bryzgalina E.S Podhody k reanimacii vodotokov i vodnyh sistem Volgo-Ahtubinskoj pojmy (na primere Krasnoslobodskogo vodohozjajstvennogo trakta) [Approaches to the resuscitation of watercourses and water systems of the Volga-Akhtuba floodplain (on the example of Krasnoslobodsky water tract)] // Jelektronnyj nauchno-obrazovatel'nyj zhurnal VGSPU «Grani Poznanija». №4(38), 2015. S. 94-103.

5. BojcovA.G., Lastovka O.N., Kashkarova G.P., Blagova O.E. Ocenka kachestva vody po biologicheskim pokazateljam: puti sovershenstvovanija [Water quality assessment by biological indicators: ways of improvement] // Gigiena i sanitarija [Hygiene and sanitation], 2005. № 1. S. 74-77

6. Budagovskij A.I. Resursy pochvennyh vod i vodoobespechennost' rastitel'nogo pokrova [Soil water resources and water availability of vegetation] // Vodnye resursy. 1985. № 4. S. 3-13.

7. Ivancova, E.A.Al'gomonitoring raznotipnyh vodoemov Volgogradskoj oblasti / E.A. Ivancova, A.S. Karabskaja [Ligamentary different types of reservoirs of the Volgograd region] // Vestnik Volgogradskogo gosudarstvennogo universiteta. Serija 3. Jekonomika. Jekologija [Science Journal of Volgograd State University. Global Economic System] - 2016. - № 1 (34). - S. 161-168.

8. Karabskaja, A.S. Sostav al'gocenozov raznotipnyh vodoemov Volgogradskoj oblasti [The composition of algocenoses of different types of reservoirs of the Volgograd region] / A.S. Karabskaja, E.A. Ivancova // Vestnik Nizhnevartovskogo gosudarstvennogo universiteta [The Bulletin of Nizhnevartovsk State University]. - 2017. - №4. -S. 4-8.

9. Kolomin Ju.M. Jekologicheskij monitoring sostojanija vodojomov severo-kazahstanskoj oblasti $\mathrm{i}$ ispol'zovanie ih bioresursov // V sbornike: Jekologicheskij monitoring i bioraznoobrazie materialy IV mezhdunarodnoj nauchno-prakticheskoj konferencii. 2012. S. 110-113
10. Kuramshina N.G., Kuramshin Je.M., Lapikov V.V. Kompleksnyj jekologicheskij monitoring vodnyh jekosistem v uslovijah tehnogeneza [Complex ecological monitoring of water ecosystems in the conditions of technogenesis]// Jekologicheskie sistemy i pribory. - 2004. - № 8. - S. 9-11.

11. Levanova G.F., Mazepa V.N., Kashnikov S.Ju. Jekspress-metod biotestirovanija vody v polevyh uslovijah[Express-method of biotesting of water in the field] // Gigiena i sanitarija [Hygiene and sanitation], 2004. № 1. S. 64-66.

12. Novikov, V.V. Jekologicheskaja ocenka Volgogradskogo vodohranilishha po sostojaniju makrofitov i fitoplanktona [Environmental assessment of the Volgograd reservoir on the state of macrophytes and phytoplankton]/ V.V. Novikov, A.S. Karabskaja, A.I. Kochetkova, E.A. Ivancova, V.P. Zvolinskij // Vestnik Rossijskogo universiteta Druzhby narodov. Serija: Jekologija i bezopasnost' zhiznedejatel'nosti. 2014. - № 4. - S. 120-132.

13. Onishhenko G.G. Sostojanie pit'evogo vodosnabzhenija v Rossijskoj Federacii: problemy i puti reshenija [The state of drinking water supply in the Russian Federation: problems and solutions] // Gigiena i sanitarija [Hygiene and sanitation], 2007. № 1. S. 10-13.

14. Petrov B.I., Denisova S.A., Lesnov A.E. Fazovye ravnovesija i raspredelenie jelementov $\mathrm{v}$ sistemah voda - antipirin - organicheskaja kislota[Phase equilibria and distribution of elements in water - antipyrine - organic acid systems] // Izvestija Alt. gos. un-ta. - 2003. - № 3 (29). S. 230-236.

15. Rahmanin Ju.A. Prioritetnye napravlenija i kriterii ocenki zagrjaznenija okruzhajushhej sredy [Priority areas and criteria for environmental pollution assessment] //Gigiena i sanitarija [Hygiene and sanitation], 2003. № 6. S. 14-16.

16. Filippov O.V., Kochetkova A.I., Baranova M.S., Bryzgalina E.S Jekologicheskaja ocenka sostojanija vodnyh ob\#ektov VolgoAhtubinskoj pojmy v uslovijah zimnego perioda 2014 $2015 \mathrm{gg}$. [Environmental assessment of water bodies of the Volga-Akhtuba floodplain in the winter period 2014-2015] // Jelektronnyj nauchno-obrazovatel'nyj zhurnal VGSPU «Grani Poznanija». №4(38), 2015. S. 104-113. Rezhim dostupa: http://grani.vspu.ru/ jurnal/40. 


\section{Information about the Authors}

Alina V. Babicheva, Student, Professor Department of Ecology and Nature Management, Volgograd StateUniversity, Prosp. Universitetskij, 100,400062 Volgograd, Russian Federation, babicheva_alinochka@mail.ru.

Nadejda V. German, Candidate of Biology, Associate Professor Department of Ecology and Nature Management, Volgograd State University, Prosp. Universitetskij, 100, 400062 Volgograd, Russian Federation, german@volsu.ru.

\section{Информация об авторах}

Алина Валентиновна Бабичева, студент кафедры экологии и природопользования, Волгоградский государственный университет, просп. Университетский, 100, 400062 г. Волгоград, Российская Федерация, babicheva_alinochka@mail.ru.

Надежда Валерьевна Герман, кандидат биологических наук, доцент кафедры экологии и природопользования, Волгоградский государственный университет, просп. Университетский, 100, 400062 г. Волгоград, Российская Федерация, german@volsu.ru. 